\title{
SUCCESS IN SIGNALING: THE EFFECT OF FEEDBACK TO SIGNALER AND RECEIVER
}

\author{
JUSTIN SULIK $^{* 1}$ and GARY LUPYAN ${ }^{2}$ \\ *Corresponding Author: justin.sulik@gmail.com \\ ${ }^{1}$ Department of Psychology, Royal Holloway, University of London \\ ${ }^{2}$ Department of Psychology, University of Wisconsin-Madison
}

Communicating without the benefit of a conventional signaling system is hard. Generating and interpreting novel signals involves complex inferences (Levinson, 1995), which often fail. One source of failure is a tendency not to take the other person's point of view, i.e., being egocentric (Sulik \& Lupyan, under review). One solution to such difficulties is feedback (Barr, 2004; Spike, Stadler, Kirby, \& Smith, 2017; Micklos, 2016), for example in the form of information about how the recipient behaved on receiving the signal. Here, we investigate how performance in a novel signaling task is affected by various kinds of feedback. We manipulated whether feedback is provided to signaler, receiver or both, and how informative the feedback is. The topic is relevant to language evolution because it helps us understand the factors that make complex communication possible when people cannot rely on the use of conventional word-meaning associations.

Pairs of participants took part in a signaling task (Sulik \& Lupyan, 2016). Items, signals and guesses were single words. For instance, to get someone to guess 'bride', the signaler might generate the signal 'groom', which is quite likely to be successful. Alternatively, they might generate signal 'wedding' which is less likely to lead to a correct guess. Participants could generate any English word as a signal or guess (similar to the game show Password ${ }^{1}$ ). Although the signals were English words, the overall task could not make full use of a shared conventional language because it required, for example, using 'groom' or 'wedding' to mean 'bride'. The target items were selected based on published word association norms (Nelson, McEvoy, \& Schreiber, 2004), such that the participants' perspectives were aligned for some items ('symmetric' items) but not for others ('asymmetric' items).

The motivation for this unusual task is that it provides a clean measure of how informative signals are, all else being equal. In a more common gesture-based task, someone signaling 'moose' might gesture antlers, but performance is con-

\footnotetext{
${ }^{1}$ http://bit.ly/2h1ZYK0
} 
founded with the likelihood of recognizing that the gesture represents antlers, with the ease of gesturing those antlers, and with the degree of resemblance between the gesture and real antlers, which will vary between people.

Participants completed the task in pairs with each pair assigned to one of four conditions.

(1) Full feedback: the signaler was informed of the guesser's guess and the guesser was informed of the target item.

(2) Minimal feedback: both signaler and receiver received minimal feedback comprising only whether the guess was correct

(3) Signaler-only feedback: The signaler received full feedback; the receiver received no feedback.

(4) Receiver-only feedback: The receiver received full feedback; the signaler received no feedback.

Unsurprisingly, performance was better at symmetric items overall, though average performance was similar in each feedback condition. We next measured whether performance improved over the course of the game. To be clear: because participants saw each item once, we are not testing whether they discovered stable ways to signal those items through practice. Rather, our measure of improvement relates to discovering ways of succeeding at the task itself.

Overall, performance improved over time, but the improvement interacted with feedback and symmetry. For symmetric items, the improvement was independent of feedback. For asymmetric items, performance only improved when the signaler received full feedback (conditions 1 and 3). Performance in the minimal feedback and receiver-only feedback conditions ( 2 and 4 ) remained flat.

In sum, feedback had little effect when people's perspectives overlapped (symmetric items): performance improved regardless. However, when their perspectives differed, improvement at the task was driven by feedback to the signaler, though it was not enough for the signaler to just know whether they were correct or not. This investigation of factors that drive communicative success in the absence of a conventional signaling system helps us understand the prerequisites for the emergence of such a system.

\section{References}

Barr, D. J. (2004). Establishing conventional communication systems: Is common knowledge necessary? Cognitive Science, 28(6), 937-962.

Levinson, S. C. (1995). Interactional biases in human thinking. In Social intelligence and interaction (pp. 221-260). Cambridge University Press.

Micklos, A. (2016). Interaction for facilitating conventionalization: Negotiating the silent gesture communication of noun-verb pairs. In S. Roberts, C. Cuskley, L. McCrohon, L. Barceló-Coblijn, O. Feher, \& T. Verhoef (Eds.), The evolution of language: Proceedings of the 11th international conference (EVOLANG11). 
Nelson, D. L., McEvoy, C. L., \& Schreiber, T. A. (2004). The University of South Florida word association, rhyme, and word fragment norms. Behavior Research Methods, 36(3), 402-407.

Spike, M., Stadler, K., Kirby, S., \& Smith, K. (2017). Minimal requirements for the emergence of learned signaling. Cognitive science, 41(3), 623-658.

Sulik, J., \& Lupyan, G. (2016). Failures of perspective taking in an open-ended signaling task. In S. Roberts, C. Cuskley, L. McCrohon, L. Barceló-Coblijn, O. Feher, \& T. Verhoef (Eds.), The evolution of language: Proceedings of the 11th international conference (EVOLANG11).

Sulik, J., \& Lupyan, G. (under review). Perspective taking in a novel signaling task: effects of world knowledge and contextual constraint. 